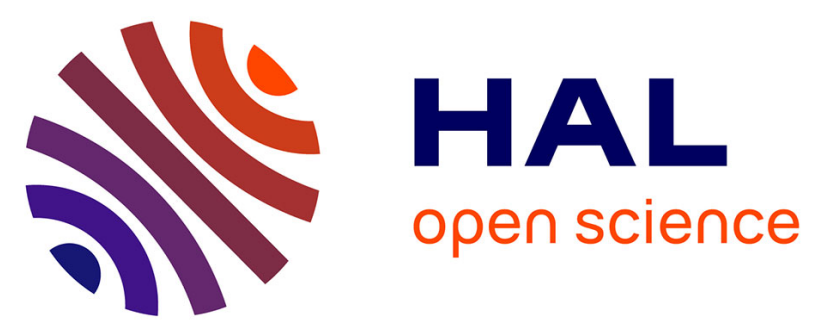

\title{
Reference values for vastus lateralis fiber size and type in healthy subjects over 40 years old: a systematic review and metaanalysis
}

Fares Gouzi, Jonathan Maury, Nicolas Molinari, Pascal Pomiès, Jacques

Mercier, Christian Prefaut, Maurice Hayot

\section{To cite this version:}

Fares Gouzi, Jonathan Maury, Nicolas Molinari, Pascal Pomiès, Jacques Mercier, et al.. Reference values for vastus lateralis fiber size and type in healthy subjects over 40 years old: a systematic review and metaanalysis. Journal of Applied Physiology, 2013, 115 (3), pp.346-354. 10.1152/japplphysiol.01352.2012 . hal-01625954

\section{HAL Id: hal-01625954 \\ https://hal.umontpellier.fr/hal-01625954}

Submitted on 29 Mar 2018

HAL is a multi-disciplinary open access archive for the deposit and dissemination of scientific research documents, whether they are published or not. The documents may come from teaching and research institutions in France or abroad, or from public or private research centers.
L'archive ouverte pluridisciplinaire HAL, est destinée au dépôt et à la diffusion de documents scientifiques de niveau recherche, publiés ou non, émanant des établissements d'enseignement et de recherche français ou étrangers, des laboratoires publics ou privés. 


\title{
Reference values for vastus lateralis fiber size and type in healthy subjects over 40 years old: a systematic review and metaanalysis
}

\author{
Fares Gouzi, ${ }^{1,2}$ Jonathan Maury, ${ }^{1,2}$ Nicolas Molinari, ${ }^{3}$ Pascal Pomiès, ${ }^{1}$ Jacques Mercier, ${ }^{1}$ \\ Christian Préfaut, ${ }^{1}$ and Maurice Hayot ${ }^{1}$ \\ ${ }^{1}$ CHRU Montpellier, Department of Clinical Physiology, University of Montpellier I and II, Montpellier, France; ${ }^{2}$ Pulmonary \\ Rehabilitation Center "La Solane," Fontalvie Group, Osséja, France; and ${ }^{3}$ CHRU Montpellier, Department of Medical \\ Information, University of Montpellier I, Montpellier, France
}

Submitted 6 November 2012; accepted in final form 29 March 2013

Gouzi F, Maury J, Molinari N, Pomiès P, Mercier J, Préfaut C, Hayot M. Reference values for vastus lateralis fiber size and type in healthy subjects over 40 years old: a systematic review and metaanalysis. J Appl Physiol 115: 346-354, 2013. First published April 4, 2013; doi:10.1152/japplphysiol.01352.2012.-Skeletal muscle atrophy is a major systemic impairment in chronic diseases. Yet its determinants have been hard to identify because a clear research definition has not been agreed upon. The reduction in muscle fiber cross-sectional area (CSA) is a widely acknowledged marker of muscle atrophy, but no reference values for the muscle fiber CSA at the age of the onset of chronic disease have ever been published. Thus, we aimed to systematically review the studies providing data on fiber CSA and fiber type proportion in the vastus lateralis of the quadriceps of healthy subjects (age $>40 \mathrm{yr}$ ) and then to pool and analyze the data from the selected studies to determine reference values for fiber CSA. We followed the guidelines of the Preferred Reporting Items for Systematic Reviews and Meta-Analyses (PRISMA) and identified 19 studies, including 423 subjects that matched the inclusion criteria. On the basis of fiber type and gender, the mean fiber CSA and the lower limits of normal (LLNs) were $\left(\%\right.$ type $\left.I^{*} 60\right)+1,743 \mu \mathrm{m}^{2}$ and $\left(\%\right.$ type $\left.\mathrm{I}^{*} 60\right)-718 \mu \mathrm{m}^{2}$, respectively, for men; and (\%type I*70) $+139 \mu \mathrm{m}^{2}$ and (\%type I*70) $1,485{\mu \mathrm{m}^{2}}^{2}$, respectively, for women. There was no significant heterogeneity among subgroups of fiber type and gender. The pooled type I fiber proportion was $50.3 \%$ ( $\mathrm{LLN}=32.9 \%$ ). In multivariate analysis, fiber CSA was significantly correlated with $\dot{\mathrm{V}}_{2}$ peak $(r=190.92$; $P=0.03)$, and type I fiber proportion was correlated with age $(r=$ -0.024; $P=0.005)$, body mass index $(r=0.096 ; P=0.005)$, and $\dot{\mathrm{V}}_{2}$ peak $(r=-0.053 ; P=0.005)$. Our metaanalysis of a homogeneous set of studies is the first to provide valuable LLNs for fiber CSA according to fiber type and gender. This analysis will be improved by prospective assessment in well-characterized healthy subjects.

skeletal muscle fiber; atrophy; chronic disease; healthy subject; elderly

SKELETAL MUSCLE ATROPHY IS a major systemic impairment in chronic diseases. In chronic obstructive pulmonary disease (COPD), this muscle atrophy has been characterized by a reduced crosssectional area (CSA) of the myofibers on the basis of biopsies from the vastus lateralis of the quadriceps (1). Similar changes have been described in chronic heart failure [CHF (48)] and in elderly subjects (13).

In clinical practice, histopathological proof of muscle atrophy is currently not mandatory in the context of chronic disease. Similarly, in research on chronic diseases and aging, the selection of subjects with atrophic muscle is not systemat-

Address for reprint requests and other correspondence: F. Gouzi, INSERM U-1046, Univ. Montpellier I, Univ. Montpellier II, Dept. of Clinical Physiology, CHRU Montpellier, 34295 Montpellier Cedex 5, France (e-mail: f-gouzi @ chu-montpellier.fr). ically based on standardized criteria (13). Despite indirect tools such as muscle imaging (6), the lack of criteria for indisputable proof of muscle atrophy has unfortunately made it difficult for researchers to identify its biological mechanisms and determinants. Reduced muscle fiber CSA on a histopathological sample is a standardized parameter of an atrophic process and may therefore be a valuable tool for research on muscle atrophy because the fiber CSA reduction directly matches the loss in myofibrillar protein (29) and increased proteolysis (30).

Reference values for muscle fiber CSA have never been published, however, particularly for healthy subjects over $40 \mathrm{yr}$ of age, which is generally the age of onset of a chronic disease (74a).

The determination of these values is a particularly complex endeavor for two reasons. First, the fiber CSA depends on the fiber type, and thus muscle fiber typing is mandatory for the assessment of fiber CSA. Second, there is a great heterogeneity of the fiber size in patients and healthy subjects, which has been observed in young subjects (62). This heterogeneity cannot be fully explained by the variability associated with the biopsy site (only 10-15\% of variation within the same muscle) (7), and is also due to genetic background (61), gender $(45,67)$, age (58), physical activity level (45), and body weight (58). Determining reference values for fiber CSA would thus require muscle biopsies in large and well-characterized populations. Another possibility might be to combine the data from control groups of healthy subjects older than $40 \mathrm{yr}$ collected from the literature. We therefore aimed to systematically review the studies providing data on fiber CSA and fiber type proportion in the vastus lateralis of the quadriceps of healthy subjects (age $>40 \mathrm{yr}$ ) and then to pool and analyze the data from the selected studies to provide reference values and lower limits of normal for muscle fiber CSA.

\section{MATERIALS AND METHODS}

This systematic review and metaanalysis was performed according to the guidelines of the Preferred Reporting Items for Systematic Reviews and Meta-Analyses (PRISMA) (50). Methods of analysis and inclusion criteria were specified before the beginning of the study and documented in a protocol. The review team was composed of clinicians in pulmonary rehabilitation, academic physiologists from a university hospital, a methodologist/statistician, and researchers. The group met four times over the course of the review.

Search strategy. A computerized literature search was performed to identify the relevant trials reported in PubMed, Web of Science, Physiotherapy Evidence Database (PEDro), and Cochrane Library from January 1967 to March 2012. Congress abstracts of the European Respiratory Society and American Thoracic Society were screened between 2001 and 2012. Additional published studies were added after analysis of reviews on the topic and on the basis of references in the articles we initially retrieved. Given our study design and the low 
risk of publication bias, unpublished sources were not included. The search was also restricted to English language literature.

A combination of the following medical subject headings (MesH) terms was used: (muscle fibers, skeletal) AND (vastus lateralis OR quadriceps OR knee-extensor OR knee-extensors OR quadriceps femoris OR muscle, quadriceps) AND (healthy subject* OR elderly OR sedentary subjects OR adult* OR aged OR patient).

To minimize information bias, the study titles and abstracts were screened by three authors (F.G., P.P., J. Maury) and the full texts of the original articles of potentially eligible studies were then retrieved to obtain complete details for inclusion. Study selection was on the basis of agreement of two authors and, in cases of disagreement, the consensus of three authors (F.G., M.H., C.P.) was sought.

Study selection. Table 1 summarizes the inclusion criteria. We included every type of clinical study (observational/comparative studies, longitudinal studies, and randomized controlled trials) in which the outcomes were fiber CSA and fiber type proportions (as at least a secondary outcome) assessed by histochemical or immunohistochemical methods. Both fiber CSA and type were mandatory because fiber CSA varies according to fiber type. The complete methodology had to be provided: biopsy site; reference for the validated technique; methodology for fiber type and size assessment; system for size measurement; and number of fibers analyzed [>100 (7)]. All the selected studies had to have been approved by a local institutional review board. The sample sizes for the CSA analysis were greater than six.

The population was restricted to healthy subjects $>40$ yr [to obtain values in healthy subjects potentially comparable with those of subjects with a chronic disease (74a)], with no condition susceptible to impact skeletal muscle function. Healthy subjects were defined according to the conclusion of a medical examination performed by a medical doctor. Obesity (70); diabetes (52); glucose intolerance (44); osteoarticular diseases (55); thyroid diseases (9); hormone replacement therapies (8); androgen, growth hormone, or insulin (66) supplementation; and statin use (49), all of which have demonstrated an effect on muscle morphology or function, constituted the noninclusion criteria. Thus, potential comorbidities and treatments of subjects had to be screened clinically. If these pieces of information were lacking in the full text of the published study, the authors of the study were contacted. If no answer was obtained, or if no medical examination with screening of comorbidities and treatments was performed, the study was excluded. Conversely, smoking status was not a criterion, because no definitive evidence of any effect of smoking on the quadriceps muscle has

Table 1. Inclusion criteria for the systematic review

\begin{tabular}{ll}
\hline \hline Inclusion Criteria & \multicolumn{1}{c}{ Description } \\
\hline Design & Any type of clinical study: \\
& Observational studies (case-control, etc.) \\
& Quasiexperimental studies (before-and-after \\
& studies, etc.) \\
& Randomized control trials \\
& Healthy subjects aged $>40$ yr \\
& No condition susceptible to impact skeletal muscle \\
Participants & function \\
& Noninclusion criteria: \\
& Obesity \\
& Diabetes \\
& Glucose intolerance \\
& Statins \\
& Osteoarticular diseases \\
& Thyroid diseases \\
& Hormone replacement therapies/androgen, growth \\
hormone or insulin supplementation & NA \\
Interventions & NA \\
Comparisons & Fiber cross-sectional area and type in the vastus \\
Outcome measure & lateralis \\
\hline & \\
& \\
&
\end{tabular}

been demonstrated (4). In addition, reduced physical activity and overweight $\left(25<\right.$ body mass index $\left.<30 \mathrm{~kg} / \mathrm{m}^{2}\right)$ were not considered as noninclusion criteria. Postoperative assessment and autopsy studies were not included because they are associated with an increased risk of bias. Studies in which CSA values were obtained on single-skinned fibers were not considered in this systematic review.

Data extraction. Data were extracted blindly and independently by two independent authors using a standardized form (see supplementary materials online) (F.G., J. Maury). When discrepancy occurred, the final data record was based on consensus (F.G., J. Maury). The authors of the selected studies were all contacted to complete and verify the data. From the eligible articles, we extracted the fiber CSA (in $\mu \mathrm{m}^{2}$ ) of all fiber types and the fiber type composition (type I/type II ratio, in \%). In addition, we extracted the age, sex ratio, body mass index, physical activity level (sedentary/no structured program, 0 ; active, 1 ; trained, 2), and $\dot{\mathrm{V}}_{2}$ peak if available, because these parameters have been incriminated in the variability of quadriceps fiber CSA (66).

Study quality assessment. The selected studies were both interventional and noninterventional, and study quality was assessed by the study design and the impact factor of the review in which the article was published. In addition, the methodological quality of the muscle histomorphological measurement and the population description were assessed for each article using a standardized questionnaire specifically designed for this very systematic review. The questionnaire items were devised by the experienced researchers and clinicians of the review team (see supplementary materials online). Finally, the risk of bias (selective reporting, redundancy, etc.) was assessed.

Statistical analysis. Quantitative data are presented as means \pm SD and qualitative data are presented with proportions. If there were subgroups, data were pooled into a single group and the SD was calculated according to the following formula:

$$
\left.\mathrm{SD}=V\left(\left(\mathrm{n}_{1} / \mathrm{ntot}\right)^{2} * \mathrm{SD}_{1}{ }^{2}\right)+\left(\left(\mathrm{n}_{2} / \text { ntot }\right)^{2} * \mathrm{SD}_{2}{ }^{2}\right)+\ldots\right)
$$

To estimate the pooled SD, we used a Markov chain Monte Carlo approach. Simulated data were generated according to each distribution (each study) and the pooled data set was used to obtain the pooled SD.

Forest plots were used to graphically evaluate both the variability [i.e., SD (74a)] of the data and the weight of each study, according to its population size. Heterogeneity between studies was assessed using the Q statistic and quantified using the $\mathrm{I}^{2}$ index (36).

Metaanalytic computations were then performed on the all-fiber type CSA and the fiber type I proportion using fixed-effect or random-effect modeling if there was significant heterogeneity on the Q-tests and/or $\mathrm{I}^{2}$ index $>50 \%$. Interrater agreement was measured using a Kappa statistic.

Differences between subgroups were tested using the $t$-test. Regressions were performed for fiber CSA and type I fiber proportion with the following covariates: age; $\mathrm{BMI}$; and $\dot{\mathrm{V}}_{2}$ peak, and using univariate and multivariate analyses with group size as the weight factor. Reference equations were established using predictors of fiber CSA and type I proportion in a stepwise, linear regression model. The models were evaluated by correlation coefficient $(r)$ and standard error of the mean (SEM). The 95\% confidence interval (CI) was calculated as follows: theoretical value \pm 1.64-residual standard deviation (SD). A measured CSA and type I fiber proportion lower than the lower limit of normal (LLN = theoretical value $-1.64 \cdot \mathrm{SD}$ ) was considered abnormal. $P<0.05$ was considered statistically significant. Analyses were performed using R.2.13.0 software (Bell Laboratories, USA).

\section{RESULTS}

Study selection. Figure 1 details the flow of studies included in the review. A final library of 19 studies involving 423 subjects $(64 \pm 1 \mathrm{yr})$ was eligible. (Table 2). Subjects were recruited worldwide, mostly from Nordic European countries 


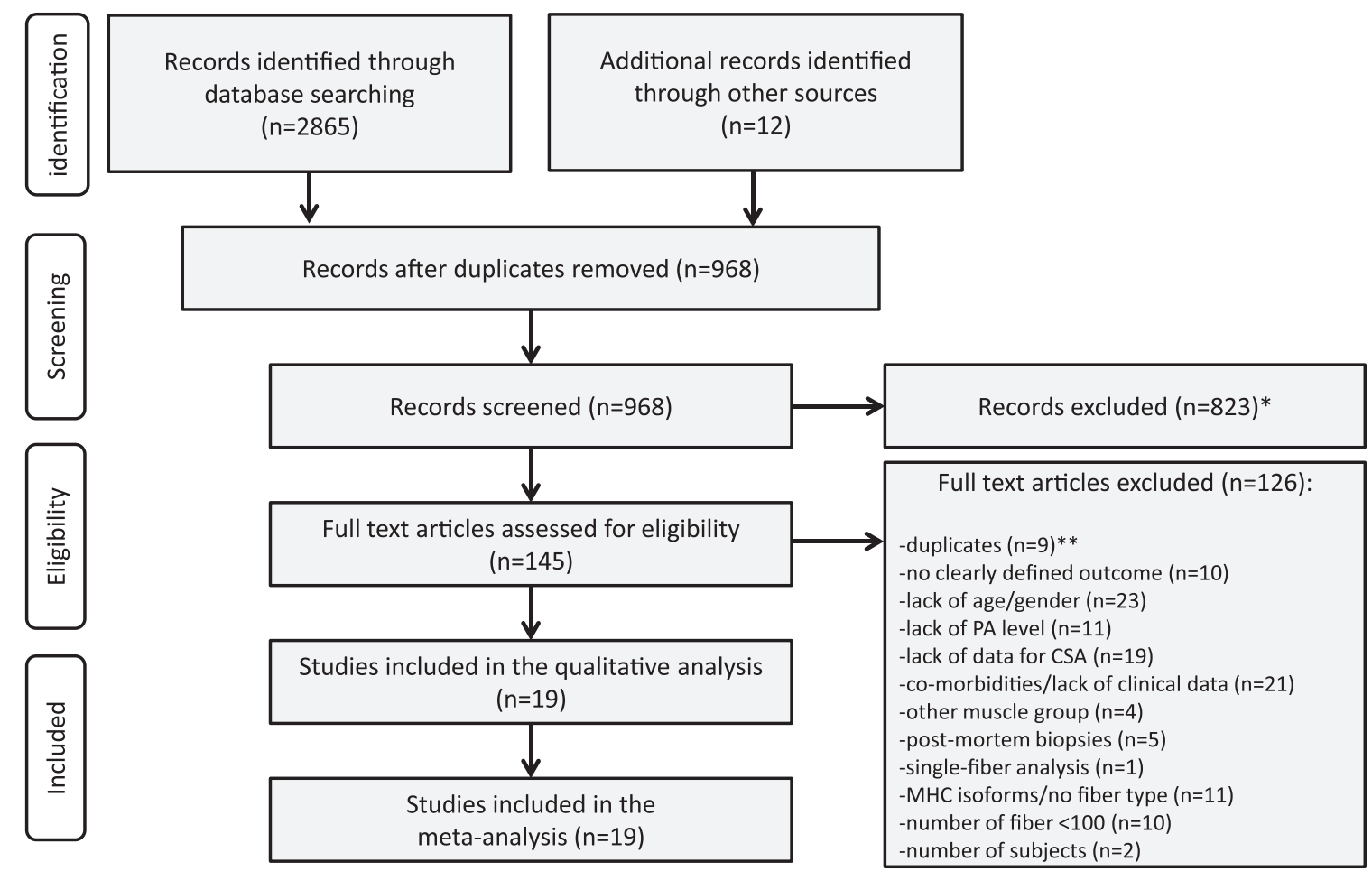

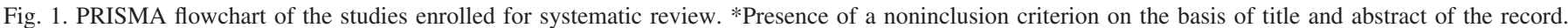
**Duplicates identified in the full-text article (population being part of a previous study).

and North America. Eighteen studies were identified from reference lists. To improve the precision of the retrieved data, the corresponding authors of 10 out of $31(32.2 \%)$ studies that could potentially be included responded to our request for data that were missing from the full texts of the retrieved manuscripts. The interrater agreement for the study selection and data extraction from the included studies was $93 \%$.

Heterogeneity and pooled results. Fiber CSA varied from $2,858 \pm 648 \mu \mathrm{m}^{2}$ (11) to $5,892 \pm 1,095 \mu \mathrm{m}^{2}$ (68). The forest plot of the fiber CSA data for all the included studies revealed the heterogeneity of the studies (Fig. 2): $\mathrm{Q}=28.1 ; P=0.06$. The corresponding $\mathrm{I}^{2}$ index reached $36 \%$. The range for the type I fiber proportion was smaller [from $44 \%$ (63) to 59\% \pm $6 \%$ (34)]. The forest plot for the type I fiber proportion showed no significant heterogeneity (Fig. 3): $\mathrm{Q}=10.2 ; P=0.85$.

The meta-analysis was performed using a fixed-effect model. The pooled estimates were 3,630 $\pm 114 \mu \mathrm{m}^{2}$ for fiber CSA (Fig. 2) and $50.3 \pm 1.9 \%$ for type I fiber proportion (Fig.

Table 2. Fiber CSA and type I proportion in the included studies

\begin{tabular}{|c|c|c|c|c|c|c|c|c|c|}
\hline Study No. & Study & $\mathrm{N}$ & Age & BMI & $\mathrm{M} / \mathrm{F}$ & Peak $\mathrm{VO}_{2}$ & Physical Activity Level & Proportion Type I & All Fiber CSA \\
\hline 1 & Essen-Gustavsson et al. 1986 (19) & 45 & $40-80$ & 24.3 & $23 / 22$ & & Active/sedentary & $0.54 \pm 0.05$ & $3749 \pm 223$ \\
\hline 2 & Cress et al. 1991 (11) & 21 & $72 \pm 6$ & 25.6 & $0 / 21$ & 19.95 & All levels & 0.47 & $2858 \pm 648$ \\
\hline 3 & Hepple et al. 1997 (34) & 9 & $65-73$ & & $9 / 0$ & $27.9 \pm 4.5$ & No structured program & $0.59 \pm 0.06$ & $3874 \pm 942$ \\
\hline 4 & Ferketich et al. 1998 (21) & 15 & $68.1 \pm 1.3$ & 24.9 & $0 / 21$ & & No structured program & $0.49 \pm 0.05$ & $4087 \pm 488$ \\
\hline 5 & Hakkinen et al. 1998 (31) & 10 & $61 \pm 4$ & 27.3 & $10 / 0$ & $27.9 \pm 1.5$ & Active & $0.48 \pm 0.09$ & $4039 \pm 700$ \\
\hline 6 & Esmarck et al. 2001 & 13 & $74 \pm 3.6$ & $25 \pm 3.6$ & $13 / 0$ & & No structured program & $0.54 \pm 0.10$ & $4164 \pm 815$ \\
\hline 7 & Widrick et al. 2003 (74) & 17 & $52.5 \pm 2.1$ & 24.3 & $0 / 17$ & & Active/sedentary & $0.38 \pm 0.06$ & $3061 \pm 391$ \\
\hline 8 & Toft et al. 2003 (66) & 51 & $60.7 \pm 2.2$ & $26.8 \pm 2.8$ & $36 / 15$ & & All levels & $0.58 \pm 0.11$ & $5154 \pm 1196$ \\
\hline 9 & Whitman et al. 2005 (73) & 21 & $73 \pm 8$ & 26.9 & $11 / 10$ & & Sedentary & $0.54 \pm 0.10$ & $4826 \pm 851$ \\
\hline 10 & Sinha-Hikim et al. 2006 (63) & 36 & $65 \pm 5$ & $27 \pm 4$ & $36 / 0$ & & No structured program & 0.44 & $3339 \pm 243$ \\
\hline 11 & Martel et al. 2006 (46) & 18 & $68.6 \pm 3.1$ & $26.3 \pm 3.1$ & $11 / 7$ & $22.4 \pm 1.3$ & No structured program & $0.49 \pm 0.07$ & $2917 \pm 356$ \\
\hline 12 & Cristea et al. 2008 (12) & 11 & $67.8 \pm 6.2$ & 23.8 & $11 / 0$ & & Trained & $0.42 \pm 0.07$ & $4572 \pm 642$ \\
\hline 13 & Green et al. 2009 (28) & 8 & $68 \pm 14$ & $27 \pm 5.7$ & $0 / 8$ & & No structured program & $0.58 \pm 0.13$ & $3372 \pm 421$ \\
\hline 14 & Verdijk et al. 2010 (68) & 59 & $72 \pm 5$ & $26.8 \pm 3.2$ & $59 / 0$ & & No structured program & $0.52 \pm 0.13$ & $5892 \pm 1095$ \\
\hline 15 & Hvid et al. 2010 (38) & 9 & $67.3 \pm 3.9$ & 26.6 & $9 / 0$ & & Active & $0.56 \pm 0.11$ & $4973 \pm 1035$ \\
\hline 16 & Vogiatzis et al. 2011 (69) & 8 & $60 \pm 5.7$ & $25.6 \pm 1.4$ & $8 / 0$ & $25.1 \pm 2.6$ & $\begin{array}{l}\text { No structured PA } \\
\text { program }\end{array}$ & $0.49 \pm 0.10$ & $3942 \pm 973$ \\
\hline 17 & Torres et al. 2011 (67) & 26 & $58 \pm 8$ & $26.7 \pm 2.7$ & $9 / 17$ & & $\begin{array}{l}\text { No structured PA } \\
\text { program }\end{array}$ & $0.53 \pm 0.08$ & $5588 \pm 1097$ \\
\hline 18 & Flueck et al. 2011 (23) & 17 & $67 \pm 2.1$ & $26.9 \pm 2.9$ & $11 / 6$ & & Active & $0.53 \pm 0.13$ & $5218 \pm 1296$ \\
\hline 19 & Gouzi et al. 2012 (27) & 23 & $61.5 \pm 5.7$ & $25.9 \pm 2.8$ & $11 / 12$ & $25.7 \pm 6$ & Sedentary & $0.45 \pm 0.11$ & $4409 \pm 1679$ \\
\hline
\end{tabular}

$\mathrm{BMI}$, body mass index; M/F, male/female ratio; CSA, cross-sectional area. 
Gouzi ERJ 2012

Flueck Scand J 2011

De Torres Respir Med 2011

Vogiatzis Chest 2011

Hvid JAP 2010

Verdijk J Am Geriatr Soc 2010

Green J Mol Histo 2009

Cristea Acta Physiol (Oxf). 2008

Martel Exp Physiol 2006

Sinha-Hikim J Clin Endocrinol Metab 2006

Whitman Pflugers arch 2005

Toft Muscle nerve 2003

Widrick J Gerontol A 2003

Esmarck J Physiol 2001

Hakkinen J Gerontol A 1998

Ferketich Acta Phys Scand 1998

Hepple Pflugers Arch 1997

Cress MSSE 1991

Essen-Gustafsson Acta Physiol Scand 1986
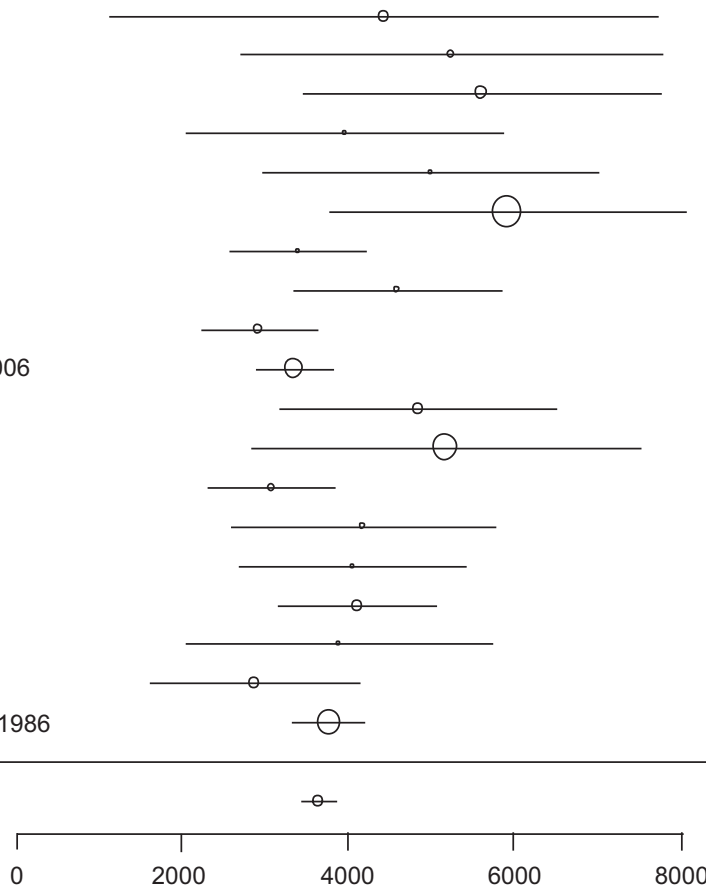

Fig. 2. Forest plot of studies reporting the fiber cross-sectional area (mean and SD, in $\mu \mathrm{m}^{2}$ ) for the 19 studies included in the systematic review.
3). Based on the variability of the selected studies, the simulated SDs were $1,352 \mu \mathrm{m}^{2}$ for fiber CSA and $10.6 \%$ for type I fiber proportion.

Post hoc subgroup comparisons showed significant differences in fiber CSA between men and women: 4,329 \pm 193 and $3,447 \pm 155 \mu \mathrm{m}^{2}$, respectively; $P<0.01$. The simulated SDs of the pooled fiber CSA in men and women were $1,501 \mu \mathrm{m}^{2}$ and $985 \mu \mathrm{m}^{2}$, respectively.

Significant differences in fiber CSA between type I and type

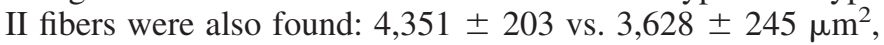
$P<0.001$ in men; and $3,829 \pm 180$ vs. $2,652 \pm 196 \mu \mathrm{m}^{2}$, $P<0.001$ in women. There was no significant heterogeneity in CSA per gender or fiber type (in men, type I $\mathrm{Q}=19, P=0.1$; type II Q $=11, P=0.54$; in women, type I Q $=4.62, P=$ 0.87 ; type II, $\mathrm{Q}=5.9, P=0.75$ ). Only 10 and 8 studies of men and women, respectively, provided results per each fiber type $(n=266)$. The resulting means and simulated SDs per gender and fiber type were as follows: men $(n=141)$ type I, 4,652 \pm 1,391, type IIa, 4,167 $\pm 1,630$, type IIx, 3,697 $\pm 1,577$; women $(n=125)$ type I, $3,840 \pm 1,587$, type IIa, 3,056 \pm 1,598; type IIx, 2,033 $\pm 1,519$.

The difference in physical activity level was also significantly different (sedentary/no structured physical activity program vs. active: $3,552 \pm 154 \mu \mathrm{m}^{2}$ vs. $4,517 \pm 408 \mu \mathrm{m}^{2} ; P<$ 0.001 ), but the sex ratio was higher in the sedentary subgroup than in the active subgroup (men/women: 52/6 vs. 167/75),

\section{Gouzi ERJ 2012}

Flueck Scand J 2011

De Torres Respir Med 2011

Vogiatzis Chest 2011

Hvid JAP 2010

Verdijk J Am Geriatr Soc 2010

Green J Mol Histo 2009

Cristea Acta Physiol (Oxf). 2008

Martel Exp Physiol 2006

Whitman Pflugers arch 2005

Toft Muscle nerve 2003

Widrick J Gerontol A 2003

Esmarck J Physiol 2001

Hakkinen J Gerontol A 1998

Ferketich Acta Phys Scand 1998

Hepple Pflugers Arch 1997

Essen-Gustafsson Acta Physiol Scand 1986

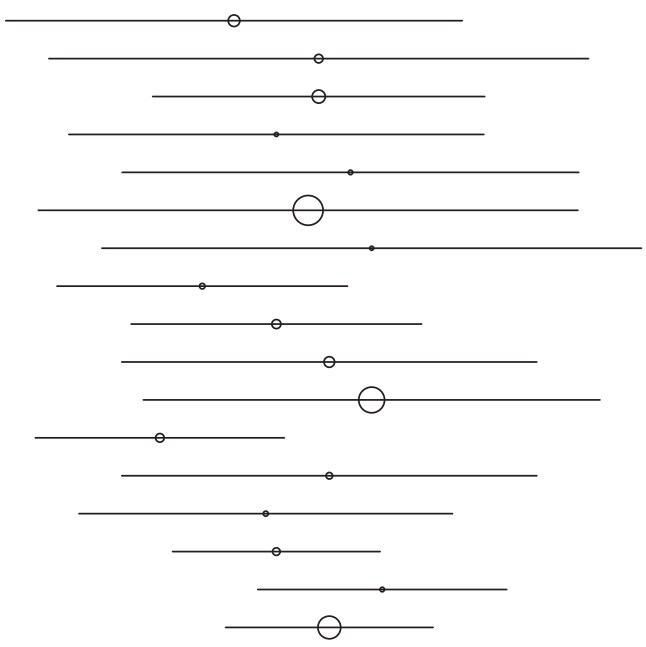

Fig. 3. Forest plot of studies reporting the type I fiber proportion (mean and SD, in \%) for the 19 studies included in the systematic review.

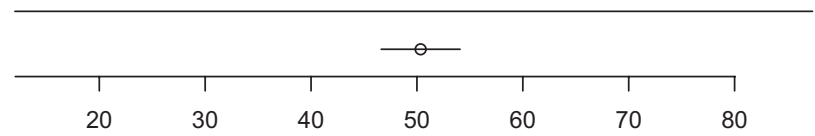


suggesting that the increased fiber CSA in the active group may have been the effect of the higher proportion of men in this latter group. There was no significant difference between men and women in type I fiber proportion: $53.9 \pm 2.8$ and $48.1 \pm$ 2.6 , respectively, $P=0.33$; nor between sedentary/no structured physical activity program and active: $53.2 \pm 2.3$ and $47.4 \pm 4.6$, respectively, $P=0.41$.

Regression analyses. The univariate analysis showed significant correlations between fiber CSA and body mass index $(P=0.057), \dot{V}_{O_{2} \text { peak }}(P=0.035)$, and type $\mathrm{I}$ fibers $(P=$ $0.035)$. In multivariate analysis, only $\dot{\mathrm{V}}_{\mathrm{O}_{2} \text { peak }}$ remained significant $(\beta=190.92, P=0.03$; see Table 3 ). In multivariate analysis (see Table 4 and Fig. 4), we found significant correlations between type I fiber proportion and age $(\beta=-0.024 ; P=0.005)$, body mass index $(\beta=0.096 ; P=0.005)$, and $\dot{\mathrm{V}}_{2}$ peak $(\beta=$ $-0.053 ; P=0.005$ ).

Quality assessment of the studies. The interobserver agreement between F.G. and J. Maury was $>95 \%$. Quality assessment is summarized in the online supplementary materials. The main discrepancies between the studies concerned study outcomes, reporting on the management of potential pathologies and treatments, exercise capacity assessment, and number of fibers analyzed (from 104 to 387). We observed very little description of ethnic origin (in no study), physical activity level (in 9 studies), and smoking status (in 6 studies).

Prediction equations and lower/upper limits of normal. The number of studies ( $n=10$ and $n=8$ for men and women, respectively) and subjects ( $n=141$ and $n=125$ for men and women, respectively) providing data per each fiber type was not enough to determine valid LLNs, in particular for type IIx fiber in women. According to type I and type II fibers, the LLNs were $1,642 \mu \mathrm{m}^{2}$ and $593 \mu \mathrm{m}^{2}$, respectively, in men $(n=247)$; and $2,084 \mu \mathrm{m}^{2}$ and $338 \mu \mathrm{m}^{2}$, respectively, in women $(n=148)$. We also provide prediction equations and LLNs for the pooled fiber CSA per each gender and according to the type I fiber proportion, expressed in \% ( $n=267$ and $n=156$ for men and women, respectively). Given the $\beta$ of the type I fiber proportion (in \%) in the regression analysis, the prediction equations for the fiber CSA were as follows: male fiber CSA $=(\%$ type I $\cdot 60)+1,743 \mu \mathrm{m}^{2}$; female fiber CSA $=(\%$ type I $\cdot 70)+139 \mu \mathrm{m}^{2}$.

Therefore, the LLNs for fiber CSA were (\%type I-60) - 718 $\mu \mathrm{m}^{2}$ and (\%type $\left.\mathrm{I} \cdot 70\right)-1,485 \mu \mathrm{m}^{2}$, in men and women, respectively.

\section{DISCUSSION}

The major finding of our metaanalysis is that the vastus lateralis of the quadriceps of a healthy subject over $40 \mathrm{yr}$ old is characterized by a mean fiber CSA of (\%type I.60) $+1,743 \mu \mathrm{m}^{2}$ and (\%type I.70) $+139 \mu \mathrm{m}^{2}$ in men and women, respectively. The variability in the fiber CSA was explained by gender, fiber type proportion, and $\dot{\mathrm{V}}_{2}$ peak. However, this variability remained substantial in subgroups. The LLNs were thus (\%type I.60) - 718 $\mu \mathrm{m}^{2}$ and (\%type I.70) $-1,485 \mu \mathrm{m}^{2}$ in men and women, respectively.

Table 3. Multivariate regression analysis for fiber CSA

\begin{tabular}{lcrrr}
\hline \hline & Estimate $(\beta)$ & SEM & \multicolumn{1}{c}{$t$} & $P$ \\
\hline Intercept & -996 & 1,467 & -0.68 & 0.53 \\
Peak $\mathrm{VO}_{2}$ & 191 & 60 & 3.16 & 0.034 \\
\hline
\end{tabular}

Table 4. Multivariate regression analysis for type I fiber proportion

\begin{tabular}{lrlrr}
\hline \hline & Estimate $(\beta)$ & SEM & \multicolumn{1}{c}{$t$} & \multicolumn{1}{c}{$P$} \\
\hline Intercept & 0.834 & 0.009 & 92.74 & 0.007 \\
Age & -0.025 & 0.0002 & -118.19 & 0.005 \\
Body mass index & 0.096 & 0.001 & 138.27 & 0.005 \\
Peak $\mathrm{VO}_{2}$ & -0.053 & 0.0004 & -125.57 & 0.005 \\
\hline
\end{tabular}

Variability and physiological factors. Our analyses revealed that the fiber CSA depended on gender, fiber type proportion,

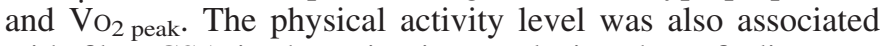
with fiber CSA in the univariate analysis. These findings are consistent with basic muscle physiology $(19,67)$ and highlight the validity of the present systematic review. Interestingly, in our multivariate regression, age was inversely correlated with type I fiber proportion, whereas a type I fiber predominance and a decrease in type II fibers has been classically reported (58). Moreover, in contrast with former studies showing reduction in all (19) and type II fiber size (54, 58), age did not alter fiber CSA in our $>40$ yr old subjects. However, over an 8-yr prospective study of healthy elderly [older than the subjects of the previous studies $(19,54,58)]$ with stable physical activity levels, no significant change in fiber type proportion or size occurred (24). These discrepancies may thus be explained by the progressive physical activity reduction associated with aging. Therefore, taking physical activity level into account in the multivariate analysis, the independent relationship between type I fiber proportion and age would be inverse. Similarly, the type I fiber proportion was positively correlated with body mass index. An increase in fiber CSA $(42,70)$ and a reduction in type I fiber proportion $(35,65)$ have been reported in obesity. Here again, taking into account the physical activity reduction (which occurs with increases in body mass index) and multivariate analysis did not reveal a correlation between body mass index and fiber CSA in our nonobese subjects.

Variability and quality assessment. The quality assessment indicated little discrepancy in the study designs and methodologies, but a low quality in reporting of populations (i.e., potential pathologies and treatments, ethnic origin, and physical activity level/exercise capacity of the subjects). In all but 1 of the 19 studies included in the review, muscle sampling was performed using the percutaneous biopsy needle technique described by Bergström (5) and modified by Evans et al. (20). Only Flueck et al. (23) used a conchotome technique, which appears to be satisfactory for most histochemical analyses (16). Thus, the fiber CSA in the study by Flueck et al. did not appear discrepant with the others. The transverse sections of the fibers were stained using the same protocols as in histochemical or immunohistochemical methods $(n=3)$. Good agreement between the two methods for assessing type I fiber proportion has been demonstrated (32).

No study detailed the subjects' ethnic origins [which may influence the muscle histomorphology $(10,41,72)]$. In addition, smoking status was mentioned in only six studies. Because smoking may have a deleterious effect on muscle function $(43,75)$ and structure $(51,53)$, this factor may explain some of the variability in the muscle histology of these healthy subjects. Last but not least, exercise capacity was assessed in 7 of the 19 studies, and physical activity level was assessed by a 

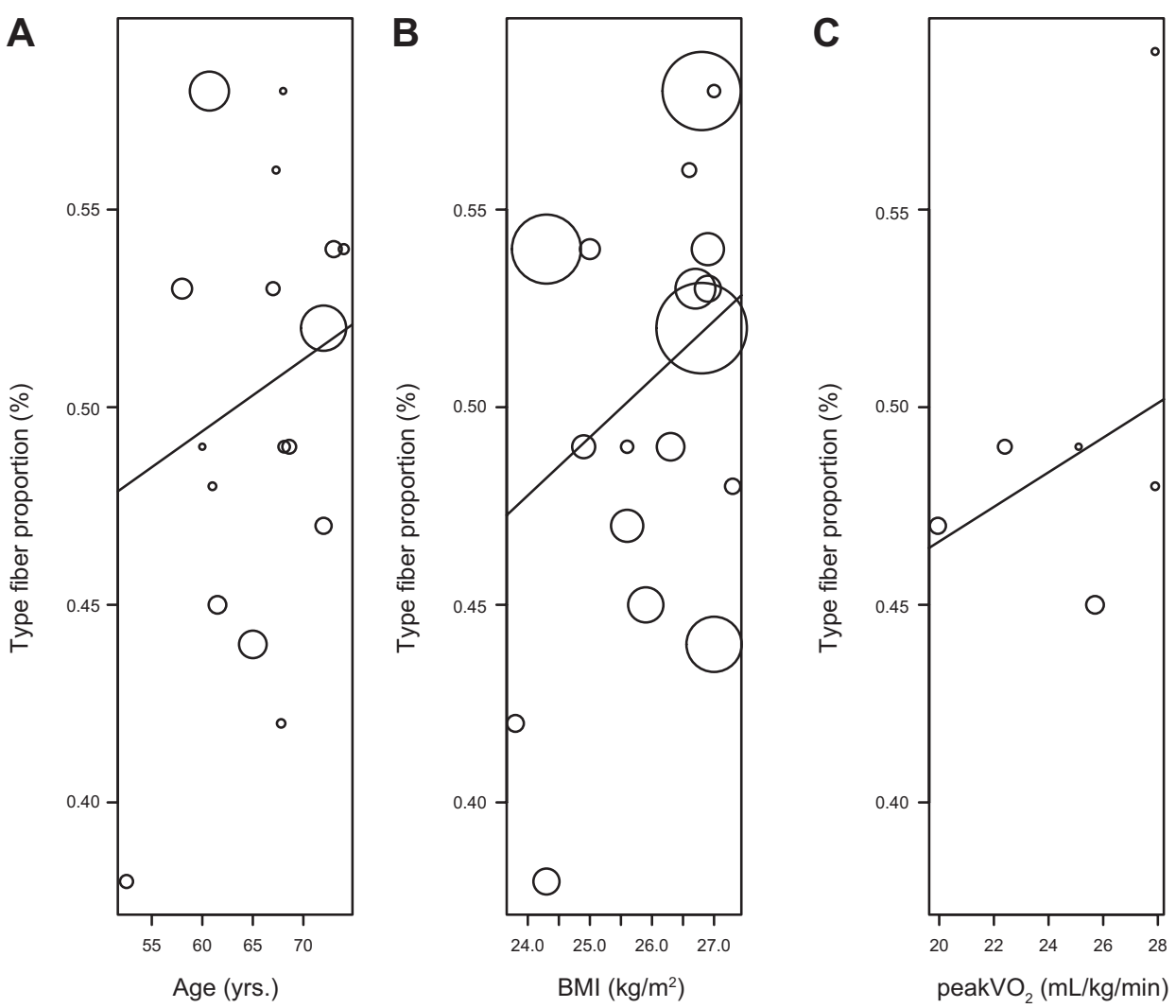

Fig. 4. Relationships between vastus lateralis fiber type I proportion and age (in years) $(A)$; body mass index (in $\left.\mathrm{kg} / \mathrm{m}^{2}\right)(B)$, and $\dot{\mathrm{V}}_{2}$ peak (in $\mathrm{ml} \cdot \mathrm{kg} \cdot \mathrm{min})(C)$. Circle sizes represent group sizes. Solid lines represent the weighted linear regression lines (if statistically significant only). Bold circles appear in cases of two overlying identical data sets. simple question in 9 of the 19 studies. Given the impact of $\dot{\mathrm{V}}_{2}$ peak and physical activity level on muscle fiber CSA and proportion, the lack of these latter data may be considered as a methodological flaw in these studies and would thus also explain an important part of the variability in the results of the present systematic review.

Conversely, healthy subjects have been defined on the basis of the same criteria, which was a direct clinical examination performed by a medical doctor, allowing the screening of clinical comorbidities and treatments. In addition, a cardiopulmonary exercise testing with measurement of maximal oxygen uptake was available in 8 of the 19 studies. Obese patients were excluded on the basis of body mass index, and at least one specific test for the screening of potential comorbidities had been performed in all studies [electrocardiogram $(n=10)$, body composition analysis $(n=7)$, spirometry $(n=4)$, muscle function test $(n=12)$, glucose tolerance test $(n=2)$, other biological assay $(n=3)]$. If each infraclinical comorbidity had not been eliminated by the multiplication of systematic investigations, the probability of including subjects with an infraclinical comorbidity and then increasing the variability of our results was reduced to its minimal. Then, the included studies would match the current highest standard for the definition of a "healthy subject" in scientific studies. This definition has constituted the basis of the definition of muscle fiber impairments observed in the context of a chronic disease. Altogether, the results are consistent with the aim of our systematic review and metaanalysis, which was to provide reference values for the vastus lateralis fiber CSA in healthy subjects, to define muscle fiber atrophy in research studies on chronic diseases.

In contrast, although the authors of the studies in our review confirmed that they did not include healthy subjects with any condition or treatment susceptible to impact muscle morphology or function, we observed low quality of reporting of the management of potential medication and pathologies. Yet the quality of reporting does not necessarily reflect the quality of the underlying data, methods, or inclusion criteria of a population, and failure to report data or a method does not necessarily mean it has not been used $(15,37,64)$. Thus, if this incomplete reporting does not constitute a bias in our systematic review, it is an indication of the required level of reporting the definition of a healthy subject $>40 \mathrm{yr}$ in the included publications.

Reference values. Although some research groups provided reference values for fiber CSA, these data can be disputed because of the low number of subjects included $[n=74$ (26), $n=59$ (68)]. In our study, we pooled a larger number of data items $(n=423)$ from 19 studies showing relatively little heterogeneity [and nonsignificant among subgroups (36)] using a validated method to assess the mean and LLN of fiber CSA per fiber type and gender. If the variability in CSA and the number of observations lead to low LLNs per fiber type (type II in particular), the LLNs for fiber CSA according to fiber type proportion provide a relevant LLN for the usual type I fiber proportions of the vastus lateralis in patients with chronic disease.

We used a similar and appropriate systematic screening process to retrieve nine additional studies providing fiber type proportions only, but none met the inclusion criteria of our systematic review. However, because the means and SDs provided for type I fiber proportions resulted from a systematic review process, our calculation of a type I fiber proportion of $32.9 \%$ constitutes a valid LLN. In contrast, the $27 \%$ in healthy subjects provided by Gosker et al. did not result from a 
systematic review process (26). Therefore, the means and LLNs for fiber CSA per fiber type and type I fiber proportion that we present here are currently the most valid reference values for assessing the histomorphological parameters of muscle in chronic diseases.

Consistently with the observations in young subjects (62), the CVs obtained with the simulated SDs for type I and type II fibers were $38 \%$ and $51 \%$ in men and $46 \%$ and $53 \%$ in women, respectively, and $20 \%$ for the type I fiber proportion, meaning that the variability in fiber CSA and type I proportion remained high (47). Thus, given the impact of anthropometric parameters, tobacco smoking and exercise capacity/physical activity level on fiber CSA and type I proportion, these reference values could probably be improved by further inclusion of studies with well-characterized healthy subjects over $40 \mathrm{yr}$ old.

Research and clinical implications. The critical muscle event in chronic disease is the onset of atrophy because it is a prognostic factor in many chronic conditions such as COPD, CHF (25) and aging (13). However, there is currently no validated tool to define muscle atrophy (71). In research, patients/elderly subjects with muscle atrophy have been isolated according to their body mass index $(2,60)$ or physical functioning (39). This poor definition of atrophy increases the risk of false-negative results in studies aiming to isolate its underlying biological mechanisms. Cellular atrophy may be a more precise marker of muscle atrophy because it directly reflects an abnormal process in the contractile compartment of the whole organ, in contrast to muscle strength, which depends on several factors. It is therefore widely used as a marker of catabolic/anabolic imbalance. Disuse (14, 22), denervation (57), and cachexia $(56,71)$ models have demonstrated the direct and early effect on fiber CSA.

In addition, there are currently no technical limitations in assessing fiber CSA. A mini-invasive method has been validated (33), and a rapid automated image analysis system has shown promising accuracy (59). Conversely, body imaging techniques such as computed tomography (6) are limited by cost, accessibility, and concerns about radiation exposure (13). Therefore, the definition of the normal range for muscle fiber CSA will advance the research on muscle atrophy by offering the possibility of selection or stratification of subjects and patients according to occurrence of cellular atrophy. Last, the definition of subjects/patients with cellular atrophy would constitute a gold standard for validating noninvasive diagnostic tools of muscle mass assessment.

In conclusion, our study is the first to provide the lower limits of normal for fiber CSA according to fiber type. According to fiber type and gender, the LLNs for men and women were (\%type I.60) $-718 \mu \mathrm{m}^{2}$ and (\%type I.70) $-1,485 \mu \mathrm{m}^{2}$, respectively. There was no significant heterogeneity among subgroups. In addition, the LLN for type I fiber proportion was $32.9 \%$. These reference values will help to better define muscle atrophy in research studies. Ongoing work with inclusions of new studies of well-characterized populations of healthy subjects will further optimize these reference values by reducing the present variability in fiber CSA and proportions.

\section{ACKNOWLEDGMENTS}

The authors gratefully acknowledge L. Barbé from the library of the University of Montpellier I for her contribution to the retrieval of the full-text articles and all the team of "La Solane" and "La Vallonie" Pulmonary
Rehabilitation Centers for their contribution to this work. C. Stott is also acknowledged for his critical reading of the manuscript.

\section{GRANTS}

This study was supported by joint grants from the CHRU Montpellier and the patient association, APARD. F. Gouzi and J. Maury were supported by a Conventions Industrielles de Formation par la Recherche (CIFRE) grant from the Fontalvie Corporation, Toulouges, France, and the French Ministère délégué à la recherche et aux nouvelles technologies.

\section{DISCLOSURES}

No conflicts of interest, financial or otherwise, are declared by the authors.

\section{AUTHOR CONTRIBUTIONS}

Author contributions: F.G., N.M., C.-G.P., and M.H. conception and design of research; F.G. performed experiments; F.G., J. Maury, N.M., P.P., and M.H. analyzed data; F.G., J. Maury, N.M., P.P., J. Mercier, C.-G.P., and M.H. interpreted results of experiments; F.G. and N.M. prepared figures; F.G. drafted manuscript; F.G. edited and revised manuscript; F.G., J. Maury, N.M., P.P., J. Mercier, C.-G.P., and M.H. approved final version of manuscript.

\section{REFERENCES}

1. Abdellaoui A, Prefaut C, Gouzi F, Couillard A, Coisy-Quivy M, Hugon G, Molinari N, Lafontaine T, Jonquet $O$, Laoudj-Chenivesse D, Hayot M. Skeletal muscle effects of electrostimulation after COPD exacerbation: a pilot study. Eur Respir J 38: 781-788, 2011.

2. Agusti A, Morla M, Sauleda J, Saus C, Busquets X. NF-kappaB activation and iNOS upregulation in skeletal muscle of patients with COPD and low body weight. Thorax 59: 483-487, 2004.

4. Barreiro E, Peinado VI, Galdiz JB, Ferrer E, Marin-Corral J, Sanchez F, Gea J, Barbera JA. Cigarette smoke-induced oxidative stress: a role in chronic obstructive pulmonary disease skeletal muscle dysfunction. Am J Respir Crit Care Med 182: 477-488, 2010.

5. Bergström J. Percutaneous needle biopsy of skeletal muscle in physiological and clinical research. Scand J Clin Lab Invest 35: 609-616, 1975.

6. Bernard S, LeBlanc P, Whittom F, Carrier G, Jobin J, Belleau R, Maltais F. Peripheral muscle weakness in patients with chronic obstructive pulmonary disease. Am J Respir Crit Care Med 158: 629-634, 1998.

7. Blomstrand E, Celsing F, Friden J, Ekblom B. How to calculate human muscle fibre areas in biopsy samples-methodological considerations. Acta Physiol Scand 122: 545-551, 1984.

8. Carville SF, Rutherford OM, Newham DJ. Power output, isometric strength and steadiness in the leg muscles of pre- and postmenopausal women; the effects of hormone replacement therapy. Eur J Appl Physiol 96: 292-298, 2006.

9. Cheah JS, Tock EP, Kan SP. The light and electron microscopic changes in the skeletal muscles during paralysis in thyrotoxic periodic paralysis. Am J Med Sci 269: 365-374, 1975.

10. Coetzer P, Noakes TD, Sanders B, Lambert MI, Bosch AN, Wiggins T, Dennis SC. Superior fatigue resistance of elite black South African distance runners. J Appl Physiol 75: 1822-1827, 1993.

11. Cress ME, Thomas DP, Johnson J, Kasch FW, Cassens RG, Smith EL, Agre JC. Effect of training on VO2max, thigh strength, and muscle morphology in septuagenarian women. Med Sci Sports Exerc 23: 752-758, 1991.

12. Cristea A, Korhonen MT, Häkkinen K, Mero A, Alén M, Sipilä S, Viitasalo JT, Koljonen MJ, Suominen H, Larsson L. Effects of combined strength and sprint training on regulation of muscle contraction at the whole-muscle and single-fibre levels in elite master sprinters. Acta Physiol (Oxf) 193: 275-289, 2008.

13. Cruz-Jentoft AJ, Baeyens JP, Bauer JM, Boirie Y, Cederholm T, Landi F, Martin FC, Michel JP, Rolland Y, Schneider SM, Topinkova E, Vandewoude M, Zamboni M. Sarcopenia: European consensus on definition and diagnosis: report of the European Working Group on Sarcopenia in Older People. Age Ageing 39: 412-423, 2010.

14. Derde S, Hermans G, Derese I, Guiza F, Hedstrom Y, Wouters PJ, Bruyninckx F, D'Hoore A, Larsson L, Van den Berghe G, Vanhorebeek I. Muscle atrophy and preferential loss of myosin in prolonged critically ill patients. Crit Care Med 40: 79-89, 2012.

15. Devereaux PJ, Choi PT, El-Dika S, Bhandari M, Montori VM, Schünemann HJ, Garg AX, Busse JW, Heels-Ansdell D, Ghali WA, Manns BJ, Guyatt GH. An observational study found that authors of 
randomized controlled trials frequently use concealment of randomization and blinding, despite the failure to report these methods. J Clin Epidemiol 57: 1232-1236, 2004.

16. Dietrichson P, Coakley J, Smith PE, Griffiths RD, Helliwell TR, Edwards RH. Conchotome and needle percutaneous biopsy of skeletal muscle. J Neurol Neurosurg Psychiatry 50: 1461-1467, 1987.

17. Dunn AL, Marcus BH, Kampert JB, Garcia ME, Kohl HW 3rd, Blair SN. Comparison of lifestyle and structured interventions to increase physical activity and cardiorespiratory fitness: a randomized trial. JAMA 281: 327-334, 1999.

18. Esmarck B, Andersen JL, Olsen S, Richter EA, Mizuno M, Kjaer M. Timing of postexercise protein intake is important for muscle hypertrophy with resistance training in elderly humans. J Physiol 535: 301-311, 2001

19. Essén-Gustavsson B, Borges O. Histochemical and metabolic characteristics of human skeletal muscle in relation to age. Acta Physiol Scand 126 107-114, 1986.

20. Evans WJ, Phinney SD, Young VR. Suction applied to a muscle biopsy maximizes sample size. Med Sci Sports Exerc 14: 101-102, 1982.

21. Ferketich AK, Kirby TE, Alway SE. Cardiovascular and muscular adaptations to combined endurance and strength training in elderly women. Acta Physiol Scand 164: 259-267, 1998.

22. Fitts RH, Riley DR, Widrick JJ. Physiology of a microgravity environment invited review: microgravity and skeletal muscle. J Appl Physiol 89: 823-839, 2000.

23. Flueck M, Eyeang-Békalé N, Hèraud A, Girard A, Gimpl M, Seynnes OR, Rittweger J, Niebauer J, Mueller E, Narici M. Load-sensitive adhesion factor expression in the elderly with skiing: relation to fiber type and muscle strength. Scand J Med Sci Sports 21, Suppl 1: 29-38, 2011.

24. Frontera WR, Reid KF, Phillips EM, Krivickas LS, Hughes VA, Roubenoff R, Fielding RA. Muscle fiber size and function in elderly humans: a longitudinal study. J Appl Physiol 105: 637-642, 2008.

25. Gosker HR, Wouters EF, van der Vusse GJ, Schols AM. Skeletal muscle dysfunction in chronic obstructive pulmonary disease and chronic heart failure: underlying mechanisms and therapy perspectives. Am J Clin Nutr 71: 1033-1047, 2000.

26. Gosker HR, Zeegers MP, Wouters EF, Schols AM. Muscle fibre type shifting in the vastus lateralis of patients with COPD is associated with disease severity: a systematic review and meta-analysis. Thorax 62: 944-949, 2007.

27. Gouzi F, Préfaut C, Abdellaoui A, Roudier E, de Rigal P, Molinari N, Laoudj-Chenivesse D, Mercier J, Birot O, Hayot M. Blunted muscle angiogenic training-response in COPD patients vs. sedentary controls. Eur Respir J 41: 806-814, 2013.

28. Green HJ, Burnett ME, D’Arsigny C, Iqbal S, Ouyang J, Webb KA, O'Donnell DE. Muscle fiber type characteristics in females with chronic obstructive pulmonary disease. A preliminary study. J Mol Histol 40: 41-51, 2009.

29. Haddad F, Roy RR, Zhong H, Edgerton VR, Baldwin KM. Atrophy responses to muscle inactivity. I. Cellular markers of protein deficits. $J$ Appl Physiol 95: 781-790, 2003.

30. Haddad F, Roy RR, Zhong H, Edgerton VR, Baldwin KM. Atrophy responses to muscle inactivity. II. Molecular markers of protein deficits. $J$ Appl Physiol 95: 791-802, 2003.

31. Hakkinen K, Newton RU, Gordon SE, McCormick M, Volek JS, Nindl BC, Gotshalk LA, Campbell WW, Evans WJ, Hakkinen A, Humphries BJ, Kraemer WJ. Changes in muscle morphology, electromyographic activity, and force production characteristics during progressive strength training in young and older men. J Gerontol A Biol Sci Med Sci 53: B415-B423, 1998.

32. Havenith MG, Visser R, Schrijvers-van Schendel JM, Bosman FT. Muscle fiber typing in routinely processed skeletal muscle with monoclonal antibodies. Histochemistry 93: 497-499, 1990.

33. Hayot M, Michaud A, Koechlin C, Caron MA, Leblanc P, Prefaut C, Maltais F. Skeletal muscle microbiopsy: a validation study of a minimally invasive technique. Eur Respir J 25: 431-440, 2005.

34. Hepple RT, Mackinnon SL, Thomas SG, Goodman JM, Plyley MJ. Quantitating the capillary supply and the response to resistance training in older men. Pflugers Arch 433: 238-244, 1997.

35. Hickey MS, Carey JO, Azevedo JL, Houmard JA, Pories WJ, Israel RG, Dohm GL. Skeletal muscle fiber composition is related to adiposity and in vitro glucose transport rate in humans. Am J Physiol Endocrinol Metab 268: E453-E457, 1995.
36. Higgins J, Green S. Cochrane handbook for systematic reviews of interventions. Version 5.1.0 [updated March 2011]. The Cochrane Collaboration, 2011.

37. Hill CL, LaValley MP, Felson DT. Discrepancy between published report and actual conduct of randomized clinical trials. J Clin Epidemiol 55: 783-786, 2002.

38. Hvid L, Aagaard P, Justesen L, Bayer ML, Andersen JL, Ørtenblad N, Kjaer M, Suetta C. Effects of aging on muscle mechanical function and muscle fiber morphology during short-term immobilization and subsequent retraining. J Appl Physiol 109: 1628-1634, 2010.

39. Joseph AM, Adhihetty PJ, Buford TW, Wohlgemuth SE, Lees HA, Nguyen LM, Aranda JM, Sandesara BD, Pahor M, Manini TM, Marzetti E, Leeuwenburgh C. The impact of aging on mitochondrial function and biogenesis pathways in skeletal muscle of sedentary highand low-functioning elderly individuals. Aging Cell 11: 801-809, 2012.

40. Kadiiska MB, Gladen BC, Baird DD, Germolec D, Graham LB, Parker CE, Nyska A, Wachsman JT, Ames BN, Basu S, Brot N, Fitzgerald GA, Floyd RA, George M, Heinecke JW, Hatch GE, Hensley K, Lawson JA, Marnett LJ, Morrow JD, Murray DM, Plastaras J, Roberts LJ 2nd, Rokach J, Shigenaga MK, Sohal RS, Sun J, Tice RR, Van Thiel DH, Wellner D, Walter PB, Tomer KB, Mason RP, Barrett JC. Biomarkers of oxidative stress study II: are oxidation products of lipids, proteins, and DNA markers of $\mathrm{CCl} 4$ poisoning? Free Radic Biol Med 38: 698-710, 2005.

41. Kohn TA, Essen-Gustavsson B, Myburgh KH. Do skeletal muscle phenotypic characteristics of Xhosa and Caucasian endurance runners differ when matched for training and racing distances? J Appl Physiol 103: 932-940, 2007.

42. Krotkiewski M, Björntorp P. Muscle tissue in obesity with different distribution of adipose tissue. Effects of physical training. Int J Obes 10: 331-341, 1986.

43. Kumar PR, Kumar NV. Effect of cigarette smoking on muscle strength of flexibility of athletes. Indian J Exp Biol 36: 1144-1146, 1998.

44. Larsson H, Daugaard JR, Kiens B, Richter EA, Ahren B. Muscle fiber characteristics in postmenopausal women with normal or impaired glucose tolerance. Diabetes Care 22: 1330-1338, 1999.

45. Lortie G, Simoneau JA, Hamel P, Boulay MR, Bouchard C. Relationships between skeletal muscle characteristics and aerobic performance in sedentary and active subjects. Eur J Appl Physiol Occup Physiol 54: 471-475, 1985.

46. Martel GF, Roth SM, Ivey FM, Lemmer JT, Tracy BL, Hurlbut DE, Metter EJ, Hurley BF, Rogers MA. Age and sex affect human muscle fibre adaptations to heavy-resistance strength training. Exp Physiol 91: 457-464, 2006

47. Martin L, Gendron A. Méthodes statistiques appliquées à la psychologie: Traitement de données avec Excel. Trois-Rivières, Quebec, CA, 2004, p. 904.

48. Middlekauff HR. Making the case for skeletal myopathy as the major limitation of exercise capacity in heart failure. Circ Heart Fail 3: 537-546, 2010.

49. Mohaupt MG, Karas RH, Babiychuk EB, Sanchez-Freire V, Monastyrskaya K, Iyer L, Hoppeler H, Breil F, Draeger A. Association between statin-associated myopathy and skeletal muscle damage. CMAJ 181: E11-E18, 2009.

50. Moher D, Liberati A, Tetzlaff J, Altman DG. Preferred reporting items for systematic reviews and meta-analyses: the PRISMA statement. PLoS Med 6: e1000097, 2009.

51. Montes de Oca M, Loeb E, Torres SH, De Sanctis J, Hernandez N, Talamo C. Peripheral muscle alterations in non-COPD smokers. Chest 133: 13-18, 2008.

52. Oberbach A, Bossenz Y, Lehmann S, Niebauer J, Adams V, Paschke R, Schon MR, Bluher M, Punkt K. Altered fiber distribution and fiber-specific glycolytic and oxidative enzyme activity in skeletal muscle of patients with type 2 diabetes. Diabetes Care 29: 895-900, 2006.

53. Orlander J, Kiessling KH, Larsson L. Skeletal muscle metabolism, morphology and function in sedentary smokers and nonsmokers. Acta Physiol Scand 107: 39-46, 1979.

54. Proctor DN, Sinning WE, Walro JM, Sieck GC, Lemon PW. Oxidative capacity of human muscle fiber types: effects of age and training status. $J$ Appl Physiol 78: 2033-2038, 1995.

55. Reardon K, Galea M, Dennett X, Choong P, Byrne E. Quadriceps muscle wasting persists 5 months after total hip arthroplasty for osteoarthritis of the hip: a pilot study. Intern Med J 31: 7-14, 2001. 
56. Reed SA, Sandesara PB, Senf SM, Judge AR. Inhibition of FoxO transcriptional activity prevents muscle fiber atrophy during cachexia and induces hypertrophy. FASEB J 26: 987-1000, 2012.

57. Rowan SL, Rygiel K, Purves-Smith FM, Solbak NM, Turnbull DM, Hepple RT. Denervation causes fiber atrophy and myosin heavy chain co-expression in senescent skeletal muscle. PLoS One 7: e29082, 2012.

58. Scelsi R, Marchetti C, Poggi P. Histochemical and ultrastructural aspects of $\mathrm{m}$. vastus lateralis in sedentary old people (age 65-89 years). Acta Neuropathol 51: 99-105, 1980.

59. Sertel O, Dogdas B, Chiu CS, Gurcan MN. Microscopic image analysis for quantitative characterization of muscle fiber type composition. Comput Med Imaging Graph 35: 616-628, 2011.

60. Siednienko J, Jankowska EA, Banasiak W, Gorczyca WA, Ponikowski P. Nuclear factor-kappaB activity in peripheral blood mononuclear cells in cachectic and non-cachectic patients with chronic heart failure. Int J Cardiol 122: 111-116, 2007.

61. Simoneau JA, Bouchard C. Genetic determinism of fiber type proportion in human skeletal muscle. FASEB J 9: 1091-1095, 1995.

62. Simoneau JA, Bouchard C. Human variation in skeletal muscle fibertype proportion and enzyme activities. Am J Physiol Endocrinol Metab 257: E567-E572, 1989.

63. Sinha-Hikim I, Cornford M, Gaytan H, Lee ML, Bhasin S. Effects of testosterone supplementation on skeletal muscle fiber hypertrophy and satellite cells in community-dwelling older men. J Clin Endocrinol Metab 91: 3024-3033, 2006

64. Soares HP, Daniels S, Kumar A, Clarke M, Scott C, Swann S, Djulbegovic B. Bad reporting does not mean bad methods for randomised trials: observational study of randomised controlled trials performed by the Radiation Therapy Oncology Group. BMJ 328: 22-24, 2004.

65. Tanner CJ, Barakat HA, Dohm GL, Pories WJ, MacDonald KG, Cunningham PR, Swanson MS, Houmard JA. Muscle fiber type is associated with obesity and weight loss. Am J Physiol Endocrinol Metab 282: E1191-E1196, 2002.

66. Toft I, Lindal S, Bonaa KH, Jenssen T. Quantitative measurement of muscle fiber composition in a normal population. Muscle Nerve 28: 101-108, 2003.
67. Torres SH, Montes de Oca M, Loeb E, Mata A, Hernandez N. Gender and skeletal muscle characteristics in subjects with chronic obstructive pulmonary disease. Respir Med 105: 88-94, 2011.

68. Verdijk LB, Snijders T, Beelen M, Savelberg HH, Meijer K, Kuipers H, Van Loon LJ. Characteristics of muscle fiber type are predictive of skeletal muscle mass and strength in elderly men. J Am Geriatr Soc 58: 2069-2075, 2010.

69. Vogiatzis I, Terzis G, Stratakos G, Cherouveim E, Athanasopoulos D, Spetsioti S, Nasis I, Manta P, Roussos C, Zakynthinos S. Effect of pulmonary rehabilitation on peripheral muscle fiber remodeling in patients with COPD in GOLD stages II to IV. Chest 140: 744-752, 2011.

70. Wade AJ, Marbut MM, Round JM. Muscle fibre type and aetiology of obesity. Lancet 335: 805-808, 1990.

71. Weber MA, Kinscherf R, Krakowski-Roosen H, Aulmann M, Renk H, Kunkele A, Edler L, Kauczor HU, Hildebrandt W. Myoglobin plasma level related to muscle mass and fiber composition: a clinical marker of muscle wasting? J Mol Med (Berl) 85: 887-896, 2007.

72. Weston AR, Karamizrak O, Smith A, Noakes TD, Myburgh KH African runners exhibit greater fatigue resistance, lower lactate accumulation, and higher oxidative enzyme activity. J Appl Physiol 86: 915-923, 1999

73. Whitman SA, Wacker MJ, Richmond SR, Godard MP. Contributions of the ubiquitin-proteasome pathway and apoptosis to human skeletal muscle wasting with age. Pflugers Arch 450: 437-446, 2005.

74. Widrick JJ, Maddalozzo GF, Lewis D, Valentine BA, Garner DP, Stelzer JE, Shoepe TC, Snow CM. Morphological and functional characteristics of skeletal muscle fibers from hormone-replaced and nonreplaced postmenopausal women. J Gerontol A Biol Sci Med Sci 58: 3-10, 2003

74a.World Health Organization. Global status report on noncommunicable disease 2010. Geneva: World Health Organization, Department of Chronic Diseases and Health Promotion, 2011.

75. Wust RC, Morse CI, de Haan A, Rittweger J, Jones DA, Degens H. Skeletal muscle properties and fatigue resistance in relation to smoking history. Eur J Appl Physiol 104: 103-110, 2008 